Aquaculture

October 2017, Volume 479, Pages 742-749

http://dx.doi.org/10.1016/..aquaculture.2017.07.012

http://archimer.ifremer.fr/doc/00392/50314/

(c) 2017 Elsevier B.V. All rights reserved.

\title{
Estimates of genetic variability and inbreeding in experimentally selected populations of European sea bass
}

\author{
Hillen J.E.J. ${ }^{1,{ }^{*}}$, Coscia I. ${ }^{1}$, Vandeputte Marc ${ }^{2,3}$, Herten K. ${ }^{4}$, Hellemans B. ${ }^{1}$, Maroso F. ${ }^{3,5}$, \\ Vergnet Alain ${ }^{3}$, Allal Francois ${ }^{3}$, Maes G.E. ${ }^{1,5}$, Volckaert F.A.M. ${ }^{1}$
}

${ }^{1}$ Laboratory of Biodiversity and Evolutionary Genomics, University of Leuven, B-3000 Leuven, Belgium

${ }^{2}$ GABI, INRA, AgroParisTech, Université Paris-Saclay, F-78350 Jouy-en-Josas, France

${ }^{3}$ Ifremer, UMR9190 MARBEC, Chemin de Maguelone, F-34250 Palavas-les-Flots, France

${ }^{4}$ Laboratory for Cytogenetics and Genome Research, Center for Human Genetics, Genomics Core,

University of Leuven, B-3000 Leuven, Belgium

${ }^{5}$ Department of Compared Biomedicine and Food Science, University of Padova, I-5020 Legnaro, Italy

* Corresponding author : J.E.J. Hillen, email address : jasmienhillen@gmail.com

\begin{abstract}
:
The aquaculture industry has increasingly aimed at improving economically important traits like growth, feed efficiency and resistance to infections. Artificial selection represents an important window of opportunity to significantly improve production. However, the pitfall is that selection will reduce genetic diversity and increase inbreeding in the farmed stocks. Genetic tools are very useful in this context as they provide accurate measures of genetic diversity together with many additional insights in the stock status and the selection process. In this study we assessed the level of genetic variability and relatedness over several generations of two lines of experimentally selected European sea bass (Dicentrarchus labrax L.). The first line was selected for growth over three generations and the second line for both high and low weight loss under a starvation regime over two generations. We used a genomic approach (2549 single nucleotide polymorphism markers derived from double digest restriction site associated DNA sequencing) in combination with eight microsatellites to estimate genetic variation, relatedness, effective population size and genetic differentiation across generations. Individual heterozygosity estimates indicated that the selected lines showed no significant reduction in diversity compared with wild populations. There was, however, a decreasing trend in allelic richness, suggesting the loss of low frequency alleles. We compared the estimates of effective population size from genetic markers with pedigree information and found good correspondence between methods. This study provides important insights in the genetic consequences of selective breeding and demonstrates the operational use of the latest genomic tools to estimate variability, inbreeding and at a later stage domestication and artificial selection.
\end{abstract}




\section{Highlights}

- We used 2,549 genome-wide SNP markers to study changes in genetic diversity due to artificial selection for growth and weight loss after starvation in European sea bass, one of the most important aquaculture species in Europe. We found no strong evidence for decreased genetic diversity after three generations of experimental selection for better performance in aquaculture. Results from SNPs, microsatellites and pedigree information were consistent, indicating the validity of all three methods.

Keywords : Artificial selection, ddRAD, fish, genetic diversity, genomics, inbreeding 


\section{INTRODUCTION}

Artificial selection or selective breeding is the breeding of animals or plants in order to improve certain traits for human use. The best performing individuals are chosen and crossed to create the next generation, which is then expected to have a higher breeding value for the selected traits. Nowadays, most domesticated animals and crops have a long selection history (reviewed in Mignon-Grasteau et al. 2005), while in the aquaculture sector, selective breeding is still in its infancy (Gjedrem and Rye, 2016; Teletchea, 2009). Nevertheless, selection progress in the aquaculture sector is expected to be fast because many aquatic species have a high fecundity, allowing stringent selection and faster gains (Gjedrem et al., 2012). Nowadays, this potential for genetic improvement in fish, shellfish and seaweed is increasingly appreciated. The importance of selective breeding programs is clearly rising as it has been estimated that currently around $80 \%$ of the European farmed fish production originates from selective breeding (Janssen et al., 2016).

The long-term success of artificial selection requires a continuous balancing between broodstock size and selection pressure. Small broodstock sizes and intensive selection schemes lead to faster gains but also to nonrandom mating between individuals that are closely related (inbreeding) and consequently to a loss of genetic variation (Hedrick, 2005). The latter might reduce a population's resilience to environmental variability and hamper the potential for future selection (Williams, 2005). Inbreeding increases homozygosity as more loci will be identical by descent and leads to deleterious recessive alleles being expressed, reducing the fitness of the offspring and causing inbreeding depressions (Charlesworth and Charlesworth, 1999; Keller and Waller, 2002). In rainbow trout, for example, Pante et al. (2001) found a 1.6 to $5 \%$ lower body weight at harvest per $10 \%$ increase in the inbreeding coefficient. In order to reduce this effect, the aquaculture sector should carefully monitor and control inbreeding and designs of mating schemes, which reduce inbreeding as much as possible while still exercising a high selection differential.

The level of inbreeding in farm animals and pets is classically estimated from pedigree information, but for most commercial aquaculture facilities this is impractical and expensive for several reasons. First, it requires the separate rearing of families, physical tagging or parentage analyses of the offspring. Aquaculture fish are in many cases mass selected, making it difficult to track the contribution of the parents and establish a pedigree. Next, the history of the broodstock is often unknown or complex due to exchange or supplementation. This 
complicates the estimation of the genetic diversity of the broodstock and the differentiation of a stock from wild populations. Finally, there might be unnoticed selection for or against heterozygosity attributed to different probabilities of larval mortality (due to heterosis or genetic incompatibilities, respectively) (reviewed in Charlesworth and Willis 2009). These factors combined make proper tracking and documentation of a pedigree based breeding scheme often impractical for the aquaculture industry. Genetic tools, on the other hand, can be used to assess inbreeding based on similarity of alleles. This allows to assess the levels of inbreeding, relatedness and genetic diversity of the stock without direct information about the parents (Kardos et al., 2015).

European sea bass (Dicentrarchus labrax L.; Moronidae) is one of the most important aquaculture species in the Mediterranean Sea (FAO, 2016). Sea bass farming has been steadily increasing since the 1980s and reached a production of 153,000 tonnes in 2014 (FAO, 2016). Domestication and selective breeding started on a commercial scale in the mid-1980s (Barahona-Fernandes et al., 1977; Barnabé, 1986), when the reproductive cycle was closed through controlled spawning. Nowadays, breeding practices in sea bass are diverse: from yearly replenishment with wild fish to a closed cycle with or without selection. In 2016, seven sea bass breeding programs were operating in Europe (Chavanne et al., 2016). Traits that are economically important and typically selected for include growth, morphology, processing yields and disease resistance (Chavanne et al., 2016). However, the impact of selection on farmed sea bass remains undocumented.

This study investigated consequences of artificial selection on inbreeding and genetic variation in two experimentally selected lines of sea bass. Single nucleotide polymorphism (SNP) markers, a set of microsatellites and pedigree information were used to assess if and how genetic variation, inbreeding and effective population size changed over two or three generations of phenotypic selection.

\section{MATERIAL AND METHODS}

\subsection{Sample collection}

European sea bass (Dicentrarchus labrax L.) were sampled from two selection lines (respectively for growth and weight loss during starvation) from the experimental aquaculture station of Ifremer in Palavas-les-Flots, France (Table 1). The first line was mass selected for growth (hereafter 'growth line') over three generations. The wild 
broodstock $\left(\mathrm{F}_{0}\right)$ consisted of 33 males and 23 females, originating from the Atlantic Ocean, which were mated in a factorial design to produce the first generation, $F_{1}$. From the $F_{1}, 6$ females and 14 males were selected based on body length at one year, with an average standardised selection intensity (i) of 1.31 (equivalent to $23 \%$ selection pressure), and were mated in a factorial design to produce the second generation, $F_{2}$. From the $F_{2}, 3$ females and 30 males were selected ( $i=1.34$, equivalent to $22 \%$ selection pressure) to produce the third generation, $F_{3}$. Samples were taken from each generation of the growth line as follows: 28 fish from $F_{0}$ (sample called ' $G R W_{0}$ '), 8 fish from $F_{1}\left(G R W_{1}\right)$ and 49 fish from $F_{3}\left(G R W_{3}\right)$. The second line (see Daulé et al., 2014; Grima et al., 2010) was selected for both high and low weight loss at starvation (hereafter 'starvation line'), which is expected to be a proxy for feed conversion rate. The trait was measured as high or low weight loss under a starvation regime. The wild broodstock $\left(F_{0}\right)$ consisted of 41 males and 8 females originating from the western Mediterranean Sea, used to produce the first generation $F_{1}$ by a full factorial mating. From the $F_{1}$, new parents were selected based on their performance during two fasting periods (Daulé et al., 2014), and were mated to produce the $F_{2}$. Five $F_{1}$ females and $20 F_{1}$ males were selected for high weight loss (positive selection), with a standardised selection intensity of 1.87 (equivalent to $7.8 \%$ selection pressure), while 5 females and 20 males were selected for low weight loss (negative selection) with a standardised selection intensity of 1.78 (equivalent to $9.5 \%$ selection pressure). These positively and negatively selected broodstock were used to produce the $F_{2}$. The starvation line was sampled as follows: 19 fish from $F_{0}\left(S_{T} V_{0}\right), 29$ fish from the positively selected $F_{2}\left(S_{T} V_{2 P}\right)$ and 35 fish from the negatively selected $F_{2}\left(S_{T V} V_{2 N}\right)$ were included in this study (Table 1). Fish were anesthetized using benzocaine and fin clips from the caudal fin were collected and stored in $100 \%$ ethanol at room temperature until DNA extraction.

\subsection{Molecular methods}

Total genomic DNA was extracted using a standard salt-extraction protocol (Cruz et al., 2016) and RNA was removed with Riboshredder RNase Mixture (Epicenter, Madison, USA). DNA was stored in 5 mM Tris until library preparation. The DNA quantity was measured with the Quantlt Picogreen dsDNA assay (Thermo Fisher Scientific, Waltham, USA) and the quality was checked on a $1 \%$ agarose gel.

\subsubsection{Single nucleotide polymorphisms}


Each sample was diluted to $7 \mathrm{ng} / \mu \mathrm{L}$ and 144 individuals were pooled per library. The ddRAD library preparation followed the protocol as described in Palaiokostas et al. (2015). Samples were sequenced on an Illumina HiSeq2500 in paired-end mode at the Genomics Core of the University of Leuven (www.genomicscore.be, KU Leuven, Belgium). The raw reads were demultiplexed using GBSX v1.2 (Herten et al., 2015) allowing one mismatch per barcode. Each sample was mapped to the seabass genome (seabass_V1.0) using BOWTIE V2 2.2.4 (Langmead and Salzberg, 2012) in the end-to-end modus with seed set to one. The resulting BAM files where sorted with SAMTOOLS v1.1 (Li et al., 2009), and readgroup information was added using PICARD TOOLS v2.2.2 (Broad Institute). For each sample, all regions containing reads where extracted, using BEDTOOLS v2.23.0 (Quinlan and Hall, 2010). Regions occurring in more than $50 \%$ of the samples were extracted, resulting in 10,898 regions. FREEBAYES V1.0.233 (Garrison and Marth, 2012) was used to call the SNP variants in all samples simultaneously. The minimum mapping quality and the minimum base quality were set to 15 and 20 , respectively. The dataset was filtered using VCFTOOLS v4.1 (Danecek et al., 2011) as follows. First, indels were removed and only bi-allelic SNPs were retained. Second, the individual calls were filtered, only keeping those that had at least five supporting reads. In a next step only SNPs genotyped in at least $50 \%$ of the individuals, with a minimum quality score of 20 and a minor allele count of 3 were retained. Individuals missing more than $50 \%$ of the genotypes were removed. As a final general filtering step, SNPs were retained using a minor allele frequency threshold of $2.5 \%$. SNPs called in less than $70 \%$ of the individuals were removed. SNPs were checked for Hardy-Weinberg equilibrium (HWE), and removed if tests were significant (Minimum cut-off $p$-value $=0.001$, default setting) for half of the populations using a custom made script from: https://raw.githubusercontent.com/jpuritz/dDocent/master/scripts/filter_hwe_by_pop.pl. For SNPs in linkage disequilibrium $\left(r^{2}>0.7\right)$, all SNPs in the contig, with exception of those with the highest call rate, were discarded. This resulted in a final set of 2,549 high quality SNPs. At last, only individuals with a call rate higher than $80 \%$ were kept.

Two Fst-based outlier tests, performed on each line, identified SNPs that showed divergent Fst values compared to neutral expectations. BAYESCAN V2.1 (Foll and Gaggiotti, 2008) was run with all settings default and a false discovery rate of 0.05 . LOSITAN (Antao et al., 2008) was run with 500,000 simulations, mean neutral Fst and $95 \%$ confidence interval. Loci were considered outliers if they were detected by both methods. For the growth line this gave 186 outliers and for the starvation line 175. To obtain a neutral dataset for estimating the effective population size $\left(\mathrm{N}_{\mathrm{e}}\right)$, outliers identified by at least one method were removed from the SNP dataset. 


\subsubsection{Microsatellites}

Eight mapped microsatellites (SSR) were amplified in one multiplex reaction and genotyped for all population samples, except GRW 1 : DLA0237PY, DLA0200, DLA0106, DLA0167, DLA0104, DLA0118, DLA0036 and DLA0273e (Volckaert et al., 2012). The multiplex was performed on a 2720 Thermal Cycler (Applied Biosystems, Foster City, California, USA) in a final volume of $10 \mu$ with $5 \mu$ L QIAGEN Multiplex PCR Master Mix (QIAGEN), $3 \mu$ L RNase-free water, $1 \mu \mathrm{L}$ of the multiplexed primer combinations and $1 \mu \mathrm{L}$ template DNA. The thermocycler program involved an initial denaturation of $15 \mathrm{~min}$ at $95^{\circ} \mathrm{C}, 25$ cycles of $30 \mathrm{~s}$ at $95^{\circ} \mathrm{C}, 90 \mathrm{~s}$ at $54^{\circ} \mathrm{C}$ and $1 \mathrm{~min}$ at $72{ }^{\circ} \mathrm{C}$, and a final elongation of $30 \mathrm{~min}$ at $60^{\circ} \mathrm{C}$. Then $1 \mu \mathrm{L}$ of the PCR reaction was added to a solution of $8.8 \mu \mathrm{L}$ formamide and $0.2 \mu \mathrm{L}$ GeneScan 500 LIZ Size Standard (Applied Biosystems, Foster City, California, USA). Fragments were sized on an $\mathrm{ABI}$ Prism and analyzed by capillary electrophoresis using the 3130-Avant Genetic Analyzer (Applied Biosystems, Foster City, California, USA). GeneMAPPER v4.0 (Applied Biosystems, Foster City, California, USA) was used to score the genotypes. Panels and bins were manually constructed and all genotypes were visually checked. HWE was calculated and corrected for multiple testing using Bonferroni correction. Two (out of 40) tests had a significant $p$-value but since this was limited to one of the selected generations, the markers were kept because selected population markers are not expected to be in HWE.

\subsection{Population genetic analyses}

All analyses were performed for the SNP and microsatellite genotypes separately. Average expected $\left(H_{e}\right)$ and observed $\left(H_{\circ}\right)$ heterozygosity and inbreeding coefficient $\left(F_{I S}\right)$ at the group level were calculated using the $R(R$ Core Team, 2015) package diveRsity v1.9.89 (Keenan et al., 2013). Allelic richness was estimated using the rarefaction approach implemented in the hierfstat v0.04-26 package (Goudet and Jombart, 2016) in order to correct for sample size bias.

At the individual level, we initially estimated five commonly used measures of individual multilocus heterozygosity using the GENHET function (Coulon, 2010) in R. Correlations between these measures were tested using Pearson tests and it was found that all pairs were strongly correlated $(|r|>0.9)$ in both SNP and microsatellite datasets. Therefore we chose to report only one of the measures: standardized heterozygosity 
based on the mean observed heterozygosity (Hs_obs, Amos, 2005). This measure is highly conservative but expected to perform better in case of null alleles or allele drop-out (Amos, 2005).

$$
H s_{-} \text {obs }=\frac{(\text { number of heterozygous loci }) /(\text { number of genotyped loci })}{\text { mean observed heterozygosity of genotyped loci }}
$$

Hs_obs was tested for differences between groups (generations) within the selection lines using ANOVA. When the overall model was significant, differences among pairs of groups were further tested using a Tukey post hoc test.

Relatedness between all pairs of individuals was calculated following the methods of Queller and Goodnight (1989) and Wang (2002) as implemented in SPAGEDI (Hardy and Vekemans, 2002). Queller and Goodnight (1989) is the preferred method for SNPs whereas the method of Wang (2002) is expected to perform better with microsatellite genotypes (Ross et al., 2015). We did not specify a baseline dataset but rather used the current dataset as reference. Thousand permutations were implemented. We calculated average within-group relatedness by averaging relatedness of individual pairs of the same group.

The effective population size $\left(\mathrm{N}_{\mathrm{e}}\right)$ was estimated using the linkage disequilibrium method (Hill, 1981; Waples, 2006) implemented in NEESTIMATOR (Do et al., 2014). This method provides an estimate of the effective number of parents that produced the cohort from which the sample was drawn (Waples, 2005). The minimum allele frequency cut-off was set at 0.02 and a random mating model was selected. Confidence intervals were calculated with a jackknife procedure over individuals as described in Jones et al. (2016) and as implemented in an unreleased beta version of LDNe (Waples and Do, personal communication). For the SNP dataset, only the neutral SNP were used for $\mathrm{Ne}_{\mathrm{e}}$ calculations.

Beside the estimates based on genetic data, we used the information from the breeding scheme to calculate theoretical $\mathrm{N}_{\mathrm{e}}$ and Fis (Supplementary Table 1). The sex-ratio equation from Wright $\left(N_{e}=\frac{4 * N_{f} * N_{m}}{\left(N_{f}+N_{m}\right)}\right.$, with $\mathrm{N}_{\mathrm{f}}$ and $\mathrm{N}_{\mathrm{m}}$ the number of females and males used for spawning respectively) (Wright, 1931) was used to calculate $\mathrm{Ne}$. Based on these $\mathrm{N}_{\mathrm{e}}$ estimates, the inbreeding level accumulated over generations was recursively calculated as $F_{I S, n+1}=F_{I S, n}+\frac{1}{2 * N_{e, n}}$ with $\mathrm{F}_{\mathrm{IS}, 0}=0$ and $\mathrm{N}_{\mathrm{e}, 0}=\infty$ (and thus $\mathrm{F}_{\mathrm{IS}, 1}=\mathrm{F}_{\mathrm{IS}, 0}=0$ ). In order to compare $\mathrm{Ne}_{\mathrm{e}}$ estimates 
based on genetic markers and pedigree, the harmonic mean of the successive pedigree-based $\mathrm{NeS}$ was calculated using $\frac{1}{N_{e}}=\frac{1}{t} \sum_{i=1}^{t} \frac{1}{N_{i}}$

Finally, to obtain an insight in the genetic structure among groups and individuals, genetic variation was summarized using discriminant analysis of principal components (DAPC) as implemented in the $\mathrm{R}$ package adegenet v2.0.1 (Jombart, 2008). In this multivariate clustering method, linear combinations of the original variables (alleles) are constructed to display differences between groups as well as possible while minimizing the variation within the groups. Pairwise Fst (Nei and Chesser, 1983) was calculated to assess genetic differentiation between groups and tested for significance using ARLEQUIN v3.5.2.2 (Excoffier and Lischer, 2010).

\section{RESULTS}

\subsection{Genetic diversity}

Average SNP-He ranged between $0.194\left(\mathrm{STV}_{2 \mathrm{P}}\right)$ and $0.215\left(\mathrm{GRW}_{0}\right)$ with little difference between the groups while SSR- $\mathrm{H}_{\mathrm{e}}$ ranged between $0.625\left(\mathrm{GRW}_{3}\right)$ and $0.674\left(\mathrm{GRW}_{0}\right)$ (Table 2$)$. There was a very small decrease in $\mathrm{H}_{\mathrm{e}}$ in both datasets of the growth line, whereas this trend was only present in the SNP dataset of the starvation line. Average SNP- $H_{\circ}$ ranged between $0.192\left(\mathrm{STV}_{0}\right.$ and $\left.\mathrm{STV}_{2 \mathrm{P}}\right)$ and $0.216\left(\mathrm{GRW}_{1}\right)$ and SSR- $\mathrm{H}_{\circ}$ from $0.689\left(\mathrm{STV}_{2 \mathrm{~N}}\right)$ to $0.578\left(\mathrm{STV}_{2 \mathrm{P}}\right)$. For the growth line SNP-H $\mathrm{H}_{\mathrm{o}}$ increased in the GRW 1 group and decreased marginally in the GRW 3 group compared to GRWo; for SSR-Ho, there was a decrease from GRWo to GRW slightly for STV $2 \mathrm{~N}$ and a similar trend was observed for SSR-Ho in the starvation line. The inbreeding coefficient SNP-FIS decreased in both lines. SSR- FIS, however, increased in the growth line whereas in the starvation line it increased from STV 0 to STV $2 \mathrm{P}$ but decreased from STV 0 to STV $2 \mathrm{~N}$. FIS estimates from both genetic datasets differed remarkably from the calculated values. Allelic richness (ar) decreased slightly over the generations in both lines.

Average SNP-Hs_obs ranged from $0.947\left(\mathrm{STV}_{0}\right.$ and STV $\left.2 \mathrm{P}\right)$ to $1.063\left(\mathrm{GRW}_{1}\right)$ and SSR-Hs_obs from 0.926 (STV $\left.2 \mathrm{P}\right)$ to $1.102\left(\mathrm{STV}_{2 \mathrm{~N}}\right.$ ) (Table 2, Fig. 1). Individual measures have the advantage that they can be statistically compared. Comparisons using ANOVA showed significant differences in SNP-Hs_obs $(F(5,158)=7.845, p=1.27$ e-0.6) as well as SSR-Hs_obs $(F(5,152)=2.858, p=0.0255)$. Results of the post hoc Tukey test are presented in Fig. 1. In summary, in the growth line, there was no significant difference between the groups in both datasets. For the starvation 
line, the STV $2 \mathrm{~N}$ group had a significantly higher SNP-Hs_obs than both the STV 0 and STV $2 \mathrm{~N}$ groups while in the microsatellite data there were no significant differences within this line.

\subsection{Relatedness}

Relatedness coefficients of pairs of individuals within the same group were calculated using the methods of Queller and Goodnight (1989, raG) and Wang (2002, rw) (Fig. 2). Values close to 0 point to the absence of relatedness, while values close to 1 point to high relatedness. On average SNP-rQG was 0.246 (sd: 0.105), SSR-rQG 0.177 (sd: 0.248), SNP-rw 0.140 (sd: 0.126) and SSR- rw 0.096 (sd: 0.240). Both SNP-rw, and SNP-rag increased over the generations in both lines. SSR-rag, however, showed a decreasing trend in the starvation line and the same was observed between STV 0 and STV 2 p with SSR-rw.

\subsection{Effective population size}

$\mathrm{Ne}$ estimates based on linkage disequilibrium and pedigree showed, as expected, a large difference between parental and filial generations in both lines and datasets (Table 2). For both $\mathrm{F}_{0}$ groups $\mathrm{N}_{\mathrm{e}}$ estimates were large (SNP-N $\mathrm{N}_{\mathrm{e}}$ of 2423 for GRW and 1960 for STV $)$ ); however, these point estimates are not considered reliable as the confidence intervals included infinity. Estimating effective population size in large populations $(>1000$ individuals) is challenging because the genetic drift signal is too small to define upper boundaries to the $\mathrm{Ne}_{\mathrm{e}}$ interval (Waples and Do, 2010). There was a remarkably good agreement between estimates based on the genetic markers, especially SNPs, and pedigree information (Table 2).

\subsection{Population structure}

For the growth line, DAPC clustering showed differentiation of GRW 1 and $G R W_{3}$ from $\mathrm{GRW}_{0}$ along the first and most important axis (Fig. 3A). Also the microsatellite genotypes clearly separate $G_{R} W_{0}$ and $G_{R} W_{3}$ without overlap (Fig. 3C, only a single discriminant function is available when $n=2$ ). For the starvation line, the SNP genotypes showed that $\mathrm{STV}_{2 \mathrm{P}}$ and $\mathrm{STV}_{2 \mathrm{~N}}$ differentiated from $\mathrm{STV}_{0}$ as well as from each other (Fig. 3B). The same pattern, although less pronounced, was observed for the microsatellite genotypes (Fig. 3D).

Pairwise genetic differentiation ( $F_{S T}, \mathrm{Nei}$ and $\mathrm{Li}, 1979$ ) was significant at $p=0.05$ in almost all cases (except for $\mathrm{GRW}_{1}-\mathrm{GRW}_{3}$ in the SNP dataset) (Table 3). As expected, because they originate from different natural populations, the highest values were observed between the lines, with average Fst values of 0.221 and 0.155 in 
the SNP and microsatellite dataset, respectively. Within the growth line, SNP-Fst was on average 0.038, with the highest differentiation between $\mathrm{GRW}_{0}$ and $\mathrm{GRW}_{3}$ and $\mathrm{GRW}_{1}$ as an intermediate. SSR-F $\mathrm{F}_{\mathrm{ST}}$ between $\mathrm{GRW}_{0}$ and $\mathrm{GRW}_{3}$ was 0.071 . For the starvation line, SNP-FST was on average 0.043 , with the highest level $(0.046)$ between $\mathrm{STV}_{2 \mathrm{P}}$ and $\mathrm{STV}_{2 \mathrm{~N}}$. For the SSR-FST, the average was 0.026 and the highest values were observed $(0.029)$ between $\mathrm{STV}_{0}$ and $\mathrm{STV}_{2 \mathrm{~N}}$.

\section{DISCUSSION}

We investigated the genetic consequences of artificially selecting fish for improved performance in aquaculture. We focussed on the effects of using a reduced number of breeders to achieve high selection responses. This study is the first to report genetic changes in selected strains of sea bass using a large panel of SNP markers over several generations of selective breeding. The main finding was that there was no obvious loss of genetic diversity in heterozygosity or measurable genetic increase of inbreeding after two or three generations of intense artificial selection. However, there was a decreasing trend in allelic richness. Although the study investigated selection under experimental conditions, it provided useful insights for commercial breeding programmes.

Aquaculture practices have a tendency to reduce genetic variability and increase the level of inbreeding (e.g. Sekino et al. 2002; Lundrigan et al. 2005; Wang et al. 2012). Nevertheless, managing genetic variation in breeding programs is key to a successful outcome and consequently important to monitor. Here, we found no strong indication of genetic diversity loss during two (starvation line) or three (growth line) generations of artificial selection as measured by inbreeding coefficient and individual- or population-specific heterozygosity. However the allelic richness of both the SNPs and microsatellites showed a trend of a reduced number of alleles in later generations. Allelic richness is typically more sensitive than heterozygosity to detect reduced genetic diversity because a loss of low frequency alleles can go unnoticed in heterozygosity estimates (Allendorf, 1986; Comps et al., 2001; Norris et al., 1999; Wang et al., 2012). A decrease in allelic richness may lead to a lower adaptive potential for future generations as the diversity of raw material (standing variation) is reduced. This pattern of reduced allelic richness rather than reduced heterozygosity has been found before (e.g. Dillon and Manzi 1987; Hedgecock and Sly 1990; Yu and Guo 2004). For example, in a study on Atlantic salmon with 15 SSRs, Norris et 
al. (1999) detected $20-48 \%$ less alleles in farmed strains compared to wild ones, while heterozygosity levels were comparable.

Even though we could not point to a major loss of genetic diversity, selective breeding and domestication in commercial aquaculture will inevitably lead to increased inbreeding and changes in gene frequencies due to drift and selection. The fact that we did not find major effects could be explained by the use of factorial matings. They are more efficient at maintaining genetic variance than other types of matings (Dupont-Nivet et al., 2006) and artificial fertilization permits a better control of $\mathrm{N}_{\mathrm{e}}$ than natural matings (e.g. Chatziplis et al., 2007). In factorial mating schemes, parents from both sexes are mated to more than one partner of the opposite sex. In these matings, crosses between close relatives can be avoided (Sørensen et al., 2005). Furthermore, when directional selection is applied, the inbreeding levels were shown to be smaller in factorial breeding schemes compared to hierarchical mating (Sonesson and Meuwissen, 2000). Yet in commercial sea bass farms, mass spawning is the most used method currently (Chavanne et al., 2016).

Reduced genetic diversity linked to aquaculture practices has been well documented in many other species (e.g. Evans et al. 2004; Li et al. 2004; Alam and Islam 2005; Lundrigan et al. 2005; Li et al. 2007; Loukovitis et al. 2015) but there are surprisingly few recent studies on European sea bass (but see e.g. Bahri-Sfar et al. 2005; Brown et al. 2015; Loukovitis et al. 2015), despite its commercial importance. One previous study on genetic diversity in cultured Greek sea bass (Loukovitis et al., 2015) used five microsatellites and showed a substantially reduced allelic richness and expected heterozygosity in farms compared to wild populations. Likewise, Brown et al. (2015) and Bahri-Sfar et al. (2005) found evidence of reduced genetic variability in farmed samples compared to wild samples. However, in those cases, there was no precise information on the genetic management of the farmed stocks analysed, contrary to the present study.

Genetic differentiation between groups within the lines was significant in almost all cases. The differentiation between the parental wild origin and third (growth line) or second (starvation lines) generations is most likely the result of artificial selection in combination with founder effects and genetic drift. Significant genetic differentiation may have consequences for conservation and should also be taken into account in breeding schemes. Investigating population differentiation is a useful tool to gain understanding on commercial 
aquaculture practices because it provides insights in the origin and mixing of the aquaculture stocks and can guide the selection of new broodstock.

Maintaining a sufficiently large $\mathrm{N}_{\mathrm{e}}$ is an important measure to minimize the effect of inbreeding and loss of genetic diversity while selecting for better performance. Therefore it is important to assess the effective population size to ensure an equal parental contribution when using mass spawning. The value of $\mathrm{N}_{\mathrm{e}}$ is closely related to genetic drift and inbreeding since there is a direct relationship between $\mathrm{N}_{e}$ and inbreeding whereby $\mathrm{N}_{e}$ is equal to $1 /(2 \Delta F)$, with $\Delta F$ the per generation inbreeding rate. Here we focused on the comparison of different methods to make recommendations on methods to monitor $\mathrm{Ne}_{\mathrm{e}}$ with genetic markers. The sea bass lines used in this study were mated following full factorial mating design. Therefore the effective population size could also be derived from the pedigree information. We tested the accuracy of genetic markers for estimating $\mathrm{N}_{\mathrm{e}}$ by comparing them with pedigree based calculations and found that SNP estimates of $\mathrm{N}_{\mathrm{e}}$ were close to the values estimated from the pedigree. This means that SNPs can be adopted by industry to reliably estimate $\mathrm{N}_{\mathrm{e}}$ in breeding systems where pedigree traceability has not been implemented (typically, mass selection in mass spawning events). The microsatellites, on the other hand, did not show such a good correspondence. Previous recommendations for the $\mathrm{N}_{\mathrm{e}}$ in fish aquaculture suggested ideal sizes of 45-250 (Tave, 1993) or 100 (Gjerde, 1993; Jørstad and Nævdal, 1996) individuals. In commercial sea bass farming the number of breeders is variable (Chavanne et al., 2016); it varies from $<100$ to $>800$, although the majority of farms use $<200$ breeders and half of the companies monitor inbreeding at each generation. In commercial farms, however, mass spawning is mostly used and as a consequence the actual number of contributing parents is unknown and potentially a lot smaller than the number of fish in the tank (e.g. Hedgecock 1994; Bekkevold et al. 2002; Brown et al. 2005).

In conclusion, no significant loss of genetic diversity was found in an intensively selected and carefully managed experimental stock of European sea bass in a few generations. There was, however, a trend of decreasing allelic richness. Overall, it remains to be investigated how commercial farms, with diverse selection procedures and a diversity of follow-up procedures, will benefit from genetic monitoring. We showed that SNPs are reliable and versatile tools and recommend their application for commercial breeding.

\section{ACKNOWLEDGEMENTS}


The authors thank all Aquatrace partners, A. Chaturvedi, P. Hablützel, N. Boon, R. Waples, C. Do and two anonymous reviewers for input. Computational resources were provided by the VSC (Flemish Supercomputer Center), funded by the Research Foundation - Flanders (FWO) and the Flemish Government - department EWI. The project is funded by the 7th Framework Programme for Research (FP7) of the European Union under "Knowledge-Based Bio-Economy - KBBE", Theme 2: "Food, Agriculture and fisheries, and Biotechnologies" Project identifier: FP7-KBBE-2012-6-singlestage Grant agreement no.: 311920. J. H. was funded by a PhD scholarship of the Agency for Innovation by Science and Technology in Flanders (IWT).

\section{REFERENCES}

Alam, M.S., Islam, M.S., 2005. Population genetic structure of Catla catla (Hamilton) revealed by microsatellite DNA markers. Aquaculture 246, 151-160. doi:10.1016/j.aquaculture.2005.02.012

Allendorf, F.W., 1986. Genetic drift and the loss of alleles versus heterozygosity. Zoo Biol. 5, 181-190. doi:10.1002/zoo.1430050212

Amos, W., 2005. IR macroN3, IR Manual [WWW Document]. URL http://www.zoo.cam.ac.uk/zoostaff/amos/\#ComputerPrograms

Antao, T., Lopes, A., Lopes, R.J., Beja-Pereira, A., Luikart, G., 2008. LOSITAN: A workbench to detect molecular adaptation based on a Fst-outlier method. BMC Bioinformatics 9, 1-5. doi:10.1186/1471-2105-9-323

Bahri-Sfar, L., Lemaire, C., Chatain, B., Divanach, P., Kalthoum, O., Hassine, B., Bonhomme, F., 2005. Impact de l'élevage sur la structure génétique des populations méditerranéennes de Dicentrarchus labrax. Aquat. Living Resour. 76, 71-76. doi:10.1051/alr

Barahona-Fernandes, M.H., Girin, M., Metailler, R., 1977. Le conditionnement d'alevins de bar (Pisces, Dicentrarchus labrax) a differents aliments composés. Aquaculture 10, 53-63. doi:10.1016/00448486(77)90032-1

Barnabé, G., 1986. L' élevage du loup et de la daurade, Aquaculture: technique et documentation. Lavoisier, Paris.

Bekkevold, D., Hansen, M.M., Loeschcke, V., 2002. Male reproductive competition in spawning aggregations of cod (Gadus morhua, L .). Mol. Ecol. 11, 91-102. doi:10.1046/j.0962-1083.2001.01424.x

Brown, C., Miltiadou, D., Tsigenopoulos, C.S., 2015. Prevalence and survival of escaped European seabass Dicentrarchus labrax in Cyprus identified using genetic markers. Aquac. Environ. Interact. 7, 49-59. doi:10.3354/aei00135

Brown, R.C., Woolliams, J.A., Mcandrew, B.J., 2005. Factors influencing effective population size in commercial populations of gilthead seabream, Sparus aurata. Aquaculture 247, 219-225. doi:10.1016/j.aquaculture.2005.02.002

Charlesworth, B., Charlesworth, D., 1999. The genetic basis of inbreeding depression. Genet. Res. 74, 329-340. doi:10.1017/S0016672399004152

Charlesworth, D., Willis, J.H., 2009. The genetics of inbreeding depression. Nat. Rev. Genet. 10, 783-96. doi:10.1038/nrg2664 
Chatziplis, D., Batargias, C., Tsigenopoulos, C.S., Magoulas, A., Kollias, S., Kotoulas, G., Volckaert, F.A.M., Haley, C.S., 2007. Mapping quantitative trait loci in European sea bass (Dicentrarchus labrax): The BASSMAP pilot study. Aquaculture 272, S172-S182. doi:10.1016/j.aquaculture.2007.08.022

Chavanne, H., Janssen, K., Hofherr, J., Bargelloni, L., 2016. A comprehensive survey on selective breeding programs and seed market in the European aquaculture fish industry. Aquac. Int. 24, 1287-1307. doi:10.1007/s10499-016-9985-0

Comps, B., Gömöry, D., Letouzey, J., Thíbaut, B., Petit, R.J., 2001. Diverging trends between heterozygosity and allelic richness during postglacial colonization in the European beech. Genetics 157, 389-397.

Coulon, A., 2010. Genhet: An easy-to-use R function to estimate individual heterozygosity. Mol. Ecol. Resour. 10, 167-169. doi:10.1111/j.1755-0998.2009.02731.x

Cruz, V.P., Vera, M., Pardo, B.G., Taggart, J., Martinez, P., Oliveira, C., Foresti, F., 2016. Identification and validation of single nucleotide polymorphisms as tools to detect hybridization and population structure in freshwater stingrays. Mol. Ecol. Resour. doi:10.1111/1755-0998.12564

Danecek, P., Auton, A., Abecasis, G., Albers, C.A., Banks, E., DePristo, M.A., Handsaker, R.E., Lunter, G., Marth, G.T., Sherry, S.T., McVean, G., Durbin, R., 2011. The variant call format and VCFtools. Bioinformatics 27, 2156-2158. doi:10.1093/bioinformatics/btr330

Daulé, S., Vandeputte, M., Vergnet, A., Guinand, B., Grima, L., Chatain, B., 2014. Effect of selection for fasting tolerance on feed intake, growth and feed efficiency in the European sea bass Dicentrarchus labrax. Aquaculture 420-421, S42-S49. doi:10.1016/j.aquaculture.2013.05.036

Dillon, R.T., Manzi, J.J., 1987. Hard clam, Mercenaria mercenaria, broodstocks: Genetic drift and loss of rare alleles without reduction in heterozygosity. Aquaculture 60, 99-105. doi:10.1016/0044-8486(87)90301-2

Do, C., Waples, R.S., Peel, D., Macbeth, G.M., Tillett, B.J., Ovenden, J.R., 2014. NeEstimator v2: Reimplementation of software for the estimation of contemporary effective population size ( $\mathrm{Ne}$ ) from genetic data. Mol. Ecol. Resour. 14, 209-214. doi:10.1111/1755-0998.12157

Dupont-Nivet, M., Vandeputte, M., Haffray, P., Chevassus, B., 2006. Effect of different mating designs on inbreeding, genetic variance and response to selection when applying individual selection in fish breeding programs. Aquaculture 252, 161-170. doi:10.1016/j.aquaculture.2005.07.005

Evans, B., Bartlett, J., Sweijd, N., Cook, P., Elliott, N.G., 2004. Loss of genetic variation at microsatellite loci in hatchery produced abalone in Australia (Haliotis rubra) and South Africa (Haliotis midae). Aquaculture 233, 109-127. doi:10.1016/j.aquaculture.2003.09.037

Excoffier, L., Lischer, H.E.L., 2010. Arlequin suite ver 3.5: A new series of programs to perform population genetics analyses under Linux and Windows. Mol. Ecol. Resour. 10, 564-567. doi:10.1111/j.17550998.2010.02847.x

FAO, 2016. Fisheries and Aquaculture Department, Statistics and Information Service FishStatJ: Universal software for fishery statistical time series.

Foll, M., Gaggiotti, O., 2008. A genome-scan method to identify selected loci appropriate for both dominant and codominant markers: A Bayesian perspective. Genetics 180, 977-993. doi:10.1534/genetics.108.092221

Garrison, E., Marth, G., 2012. Haplotype-based variant detection from short-read sequencing. arXiv Prepr. arXiv1207.3907 9. doi:arXiv:1207.3907 [q-bio.GN]

Gjedrem, T., Robinson, N., Rye, M., 2012. The importance of selective breeding in aquaculture to meet future demands for animal protein: A review. Aquaculture 350-353, 117-129. doi:10.1016/j.aquaculture.2012.04.008

Gjedrem, T., Rye, M., 2016. Selection response in fish and shellfish: a review. Rev. Aquac. 
doi:10.1111/raq.12154

Gjerde, B., 1993. Breeding and selection, in: Heen, K., Monahan, R.L., Utter, F. (Eds.), Salmon Aquaculture. Fishing News Books, Cambridge USA, pp. 187-208.

Goudet, J., Jombart, T., 2016. hierfstat: Estimation and tests of hierarchical F-statistics. R package version 0.0426.

Grima, L., Vandeputte, M., Ruelle, F., Vergnet, A., Mambrini, M., Chatain, B., 2010. In search for indirect criteria to improve residual feed intake in sea bass (Dicentrarchus labrax): Part I: Phenotypic relationship between residual feed intake and body weight variations during feed deprivation and re- feeding periods. Aquaculture 300, 50-58. doi:10.1016/j.aquaculture.2010.01.003

Hardy, O.J., Vekemans, X., 2002. SPAGeDi: a versatile computer program to analyse spatial genetic structure at the individual or population levels. Mol. Ecol. Resour. 2, 618-620. doi:10.1046/j.1471-8286.2002.00305.x

Hedgecock, D., 1994. Does variance in reproductive success limit effective population size of marine organisms?, in: Genetics and Evolution of Aquatic Organisms. Chapman \& Hall, Bangor, pp. 122-134.

Hedgecock, D., Sly, F., 1990. Genetic drift and effective population sizes of hatchery-propagated stocks of the Pacific oyster, Crassostrea gigas. Aquaculture 88, 21-38. doi:10.1016/0044-8486(90)90316-F

Hedrick, P.W., 2005. Genetics of populations, 3rd ed. Jones and Barlett Publishers, Sudbury, MA.

Herten, K., Hestand, M.S., Vermeesch, J.R., Van Houdt, J.K., 2015. GBSX: a toolkit for experimental design and demultiplexing genotyping by sequencing experiments. BMC Bioinformatics 16, 73. doi:10.1186/s12859015-0514-3

Hill, W.G., 1981. Estimation of effective population-size from data on linkage disequilibrium. Genet. Res. 38, 209-216.

Janssen, K., Chavanne, H., Berentsen, P., Komen, H., 2016. Impact of selective breeding on European aquaculture. Aquaculture In press. doi:10.1016/j.aquaculture.2016.03.012

Jombart, T., 2008. Adegenet: A R package for the multivariate analysis of genetic markers. Bioinformatics 24 , 1403-1405. doi:10.1093/bioinformatics/btn129

Jones, A.T., Ovenden, J.R., Wang, Y.-G., 2016. Improved confidence intervals for the linkage disequilibrium method for estimating effective population size. Heredity (Edinb). 117, 217-223.

doi:10.1038/hdy.2016.19

Jørstad, K.E., Nævdal, G., 1996. Breeding and genetics, in: Pennell, W., Barton, B.A. (Eds.), Principles of Salmonid Culture. Elsevier, Amsterdam, pp. 655-726.

Kardos, M., Luikart, G., Allendorf, F., 2015. Measuring individual inbreeding in the age of genomics: markerbased measures are better than pedigrees. Heredity (Edinb). 11517, 63-72. doi:10.1038/hdy.2015.17

Keenan, K., McGinnity, P., Cross, T.F., Crozier, W.W., Prodöhl, P.A., 2013. diveRsity: An R package for the estimation of population genetics parameters and their associated errors. Methods Ecol. Evol. 4, 782788. doi:10.1111/2041-210X.12067

Keller, L.F., Waller, D.M., 2002. Inbreeding effects in wild populations. Trends Ecol. Evol. 17, 230-241. doi:10.1016/S0169-5347(02)02489-8

Langmead, B., Salzberg, S.L., 2012. Fast gapped-read alignment with Bowtie 2. Nat Methods 9, 357-359. doi:10.1038/nmeth.1923

Li, H., Handsaker, B., Wysoker, A., Fennell, T., Ruan, J., Homer, N., Marth, G., Abecasis, G., Durbin, R., 2009. The Sequence Alignment/Map format and SAMtools. Bioinformatics 25, 2078-2079.

doi:10.1093/bioinformatics/btp352 
Li, Q., Park, C., Endo, T., Kijima, A., 2004. Loss of genetic variation at microsatellite loci in hatchery strains of the Pacific abalone (Haliotis discus hannai). Aquaculture 235, 207-222.

doi:10.1016/j.aquaculture.2003.12.018

Li, Q., Xu, K., Yu, R., 2007. Genetic variation in Chinese hatchery populations of the Japanese scallop (Patinopecten yessoensis) inferred from microsatellite data. Aquaculture 269, 211-219. doi:10.1016/j.aquaculture.2007.04.017

Loukovitis, D., loannidi, B., Chatziplis, D., Kotoulas, G., Magoulas, A., Tsigenopoulos, C.S., 2015. Loss of genetic variation in Greek hatchery populations of the European sea bass (Dicentrarchus labrax L.) as revealed by microsatellite DNA analysis. Mediterr. Mar. Sci. 16, 197-200. doi:10.12681/mms.1033

Lundrigan, T.A., Reist, J.D., Ferguson, M.M., 2005. Microsatellite genetic variation within and among Arctic charr (Salvelinus alpinus) from aquaculture and natural populations in North America. Aquaculture 244, 63-75. doi:10.1016/j.aquaculture.2004.11.027

Mignon-Grasteau, S., Boissy, A., Bouix, J., Faure, J.M., Fisher, A.D., Hinch, G.N., Jensen, P., Le Neindre, P., Mormède, P., Prunet, P., Vandeputte, M., Beaumont, C., 2005. Genetics of adaptation and domestication in livestock. Livest. Prod. Sci. 93, 3-14. doi:10.1016/j.livprodsci.2004.11.001

Nei, M., Chesser, K., 1983. Estimation of fixation indices and gene diversities. Ann. Hum. Genet. 47, $253-259$. doi:10.1111/j.1469-1809.1983.tb00993.x

Nei, M., Li, W.H., 1979. Mathematical model for studying genetic variation in terms of restriction endonucleases. Proc. Natl. Acad. Sci. U.S.A 76: 5269-5273.

Norris, A.T., Bradley, D.G., Cunningham, E.P., 1999. Microsatellite genetic variation between and within farmed and wild Atlantic salmon (Salmo salar) populations. Aquaculture 180, 247-264. doi:10.1016/S00448486(99)00212-4

Palaiokostas, C., Bekaert, M., Khan, M.G.Q., Taggart, J.B., Gharbi, K., McAndrew, B.J., Penman, D.J., 2015. A novel sex-determining QTL in Nile tilapia (Oreochromis niloticus). BMC Genomics 16, 171. doi:10.1186/s12864-015-1383-x

Pante, M.J.R., Gjerde, B., McMillan, I., 2001. Effect of inbreeding on body weight at harvest in rainbow trout, Oncorhynchus mykiss. Aquaculture 192, 201-211. doi:10.1016/S0044-8486(00)00467-1

Queller, D.C., Goodnight, K.F., 1989. Estimating relatedness using genetic markers. Society 43, 258-275. doi:10.2307/2409206

Quinlan, A.R., Hall, I.M., 2010. BEDTools: A flexible suite of utilities for comparing genomic features. Bioinformatics 26, 841-842. doi:10.1093/bioinformatics/btq033

R Core Team, 2015. R: a language and environment for statistical computing. R Found. Stat. Comput. Vienna, Austria.

Ross, C.T., Weise, J.A., Bonnar, S., Nolin, D., Trask, J.S., Smith, D.G., Ferguson, B., Ha, J., Kubisch, H.M., 2015. An empirical comparison of short tandem repeats (STRs) and single nucleotide polymorphisms (SNPs) for relatedness estimation in Chinese Rhesus Macaques (Macaca mulatta). Am. J. Primatol. 76, 313-324. doi:10.1002/ajp.22235.An

Sekino, M., Hara, M., Taniguchi, N., 2002. Loss of microsatellite and mitochondrial DNA variation in hatchery strains of Japanese flounder Paralichthys olivaceus. Aquaculture 213, 101-122. doi:10.1016/S00448486(01)00885-7

Sonesson, A.K., Meuwissen, T.H.E., 2000. Mating schemes for optimum contribution selection with constrained rates of inbreeding. Genet. Sel. Evol. 32, 231-248. doi:10.1186/1297-9686-32-3-231

Sørensen, A.C., Berg, P., Woolliams, J. a, 2005. The advantage of factorial mating under selection is uncovered 
by deterministically predicted rates of inbreeding. Genet. Sel. Evol. GSE 37, 57-81. doi:10.1051/gse

Tave, D., 1993. Genetics for fish hatchery managers, 2nd ed. Kluwer Academic Publishers, Boston.

Teletchea, F., 2009. Molecular identification methods of fish species: reassessment and possible applications. Rev. Fish Biol. Fish. 19, 265-293. doi:10.1007/s11160-009-9107-4

Volckaert, F.A.M., Hellemans, B., Batargias, C., Louro, B., Massault, C., Van Houdt, J.K.J., Haley, C., de Koning, D.-J., Canario, A.V.M., 2012. Heritability of cortisol response to confinement stress in European sea bass Dicentrarchus labrax. Genet. Sel. Evol. 44, 15. doi:10.1186/1297-9686-44-15

Wang, J., 2002. An estimator for pairwise relatedness using molecular markers. Genetics 160, 1203-1215.

Wang, L., Shi, X., Su, Y., Meng, Z., Lin, H., 2012. Loss of genetic diversity in the cultured stocks of the large yellow croaker, Larimichthys crocea, revealed by microsatellites. Int. J. Mol. Sci. 13, 5584-5597. doi:10.3390/ijms13055584

Waples, R.S., 2006. A bias correction for estimates of effective population size based on linkage disequilibrium at unlinked gene loci. Conserv. Genet. 7, 167-184. doi:10.1007/s10592-005-9100-y

Waples, R.S., 2005. Genetic estimates of contemporary effective population size: To what time periods do the estimates apply? Mol. Ecol. 14, 3335-3352. doi:10.1111/j.1365-294X.2005.02673.x

Waples, R.S., Do, C., 2010. Linkage disequilibrium estimates of contemporary Ne using highly variable genetic markers: a largely untapped resource for applied conservation and evolution 3, 244-262.

doi:10.1111/j.1752-4571.2009.00104.x

Williams, J.L., 2005. The use of marker-assisted selection in animal breeding and biotechnology. Rev. Sci. Tech. 24, 379-91. doi:10.1.1.131.6791

Wright, S., 1931. Evolution in Mendelian populations. Genetics 16, 97-159.

Yu, Z., Guo, X., 2004. Genetic analysis of selected strains of eastern oyster (Crassostrea virginica Gmelin) using AFLP and microsatellite markers. Mar. Biotechnol. 6, 575-586. doi:10.1007/s10126-004-3600-5 
Table 1 Sampling overview: sample code and generation of the Growth and Starvation lines and number of individuals included in the SNP dataset (n SNP) and microsatellite dataset ( $n$ microsatellite). The differences in sample number between both genotyping techniques are due to technical failures.

\begin{tabular}{llll}
\hline & Generation & $n$ SNP & n microsatellite \\
\hline Growth line & & & \\
\hline GRW $_{0}$ & $F_{0}$ & 28 & $0 *$ \\
GRW & & & \\
GRW & $F_{1}$ & 8 & 47 \\
\hline Starvation line & $F_{3}$ & 47 & 19 \\
\hline STV 0 & & & 35 \\
STV $_{2 N}$ & $F_{0}$ & 18 & 28 \\
STV $_{2 P}$ & $F_{2-\text { neg }}$ & 34 & 29 \\
\hline
\end{tabular}

*excluded 
Table 2 Average basic genetic parameters at group and individual level for SNP and microsatellite (SSR) genotypes and pedigree based estimates. Observed heterozygosity $\left(\mathrm{H}_{\circ}\right)$, expected heterozygosity $\left(\mathrm{H}_{\mathrm{e}}\right)$, inbreeding coefficient $\left(\mathrm{F}_{\text {is }}\right)$ with confidence interval $(\mathrm{Cl})$ based on 1000 bootstraps, allelic richness (ar), individual standardized heterozygosity (Hs_obs) and effective population size $\left(\mathrm{N}_{\mathrm{e}}\right)$. When $\mathrm{N}_{\mathrm{e}}$ confidence intervals include infinitive $(\infty)$, this indicates that there is insufficient power to make inferences about $\mathrm{N}_{\mathrm{e}}$. For sample codes see Table 1.

\begin{tabular}{|c|c|c|c|c|c|c|}
\hline & $\mathrm{GRW}_{0}$ & $\mathrm{GRW}_{1}$ & $\mathrm{GRW}_{3}$ & $\mathrm{STV}_{0}$ & $\mathrm{STV}_{2 \mathrm{~N}}$ & $\mathrm{STV}_{2 \mathrm{P}}$ \\
\hline \multicolumn{7}{|l|}{ SNP } \\
\hline $\mathrm{H}_{\mathrm{o}}$ & 0.21 & 0.22 & 0.21 & 0.19 & 0.21 & 0.19 \\
\hline $\mathrm{H}_{\mathrm{e}}$ & 0.21 & 0.20 & 0.20 & 0.21 & 0.20 & 0.19 \\
\hline$F_{I S}$ & 0.03 & -0.08 & -0.03 & 0.05 & -0.01 & 0.00 \\
\hline $\mathrm{Cl} 95 \% \mathrm{~F}_{\mathrm{IS}}$ & $0.00-0.02$ & $-0.24--0.09$ & $-0.05--0.02$ & $0.004-0.05$ & $-0.05--0.01$ & $-0.03-0.005$ \\
\hline ar & 1.40 & 1.39 & 1.37 & 1.39 & 1.37 & 1.36 \\
\hline Hs_obs & 1.02 & 1.06 & 1.01 & 0.95 & 1.02 & 0.95 \\
\hline $\mathrm{N}_{\mathrm{e}}$ & 2423.2 & 27.6 & 21.1 & 1960.1 & 20.2 & 15.9 \\
\hline $\mathrm{Cl} 95 \% \mathrm{Ne}_{\mathrm{e}}$ & $673.5-\infty$ & $10.3-\infty$ & $17.7-25.3$ & $236.9-\infty$ & $16.8-24.7$ & $12.3-21.0$ \\
\hline \multicolumn{7}{|c|}{ Microsatellite } \\
\hline $\mathrm{H}_{\mathrm{o}}$ & 0.65 & NA & 0.58 & 0.63 & 0.69 & 0.58 \\
\hline $\mathrm{H}_{\mathrm{e}}$ & 0.67 & NA & 0.62 & 0.64 & 0.65 & 0.66 \\
\hline $\mathrm{F}_{\text {IS }}$ & 0.01 & NA & 0.04 & 0.01 & -0.04 & 0.14 \\
\hline $\mathrm{Cl} 95 \% \mathrm{~F}_{\mathrm{IS}}$ & $-0.09-0.06$ & NA & $-0.05-0.11$ & $-0.13-0.09$ & $-0.12-0.02$ & $0.03-0.21$ \\
\hline ar & 7.60 & NA & 4.99 & 6.21 & 5.69 & 5.1 \\
\hline Hs_obs & 1.04 & NA & 0.94 & 1.02 & 1.10 & 0.93 \\
\hline $\mathrm{N}_{\mathrm{e}}$ & $\infty$ & NA & 4 & $\infty$ & 12.8 & 11.8 \\
\hline $\mathrm{Cl} 95 \% \mathrm{~N}_{\mathrm{e}}$ & $77.4-\infty$ & & $2.9-8.2$ & $70.4-\infty$ & $8.6-19.2$ & $6.1-24.2$ \\
\hline \multicolumn{7}{|l|}{ Pedigree } \\
\hline $\mathrm{F}_{\text {IS }}$ & 0 & 0 & 0.04 & 0 & 0.02 & 0.02 \\
\hline $\mathrm{N}_{\mathrm{e}}$ & NA & 54.2 & 10.9 & NA & 16.0 & 16.0 \\
\hline \multicolumn{7}{|l|}{ Harmonic } \\
\hline average $\mathrm{N}_{\mathrm{e}}$ & NA & 54.2 & 17.7 & NA & 20.3 & 20.3 \\
\hline
\end{tabular}


Table 3 Pairwise Fst values (lower triangle) with associated p-values (upper triangle) for the SNP (top) and microsatellite (SSR, bottom). For abbreviations see Table 1.

\begin{tabular}{lllllll}
\hline SNP & GRW & GRW & $\mathrm{GRW}_{3}$ & $\mathrm{STV}_{0}$ & $\mathrm{STV}_{2 \mathrm{~N}}$ & $\mathrm{STV}_{2 \mathrm{P}}$ \\
\hline $\mathrm{GRW}_{0}$ & $*$ & 0.00 & 0.00 & 0.00 & 0.00 & 0.00 \\
$\mathrm{GRW}_{1}$ & $\mathbf{0 . 0 4}$ & $*$ & 0.30 & 0.00 & 0.00 & 0.00 \\
$\mathrm{GRW}_{3}$ & $\mathbf{0 . 0 7}$ & 0.00 & $*$ & 0.00 & 0.00 & 0.00 \\
$\mathrm{STV}_{0}$ & $\mathbf{0 . 1 8}$ & $\mathbf{0 . 2 1}$ & $\mathbf{0 . 2 3}$ & $*$ & 0.00 & 0.00 \\
$\mathrm{STV}_{2 \mathrm{~N}}$ & $\mathbf{0 . 1 8}$ & $\mathbf{0 . 2 2}$ & $\mathbf{0 . 2 4}$ & $\mathbf{0 . 0 4}$ & $*$ & 0.00 \\
$\mathrm{STV}_{2 \mathrm{P}}$ & $\mathbf{0 . 2 1}$ & $\mathbf{0 . 2 5}$ & $\mathbf{0 . 2 6}$ & $\mathbf{0 . 0 3}$ & $\mathbf{0 . 0 5}$ & $*$ \\
\hline
\end{tabular}

\begin{tabular}{llllll}
\hline SSR & $\mathrm{GRW}_{0}$ & $\mathrm{GRW}_{3}$ & $\mathrm{STV}_{0}$ & $\mathrm{STV}_{2 \mathrm{~N}}$ & $\mathrm{STV}_{2 \mathrm{P}}$ \\
\hline $\mathrm{GRW}_{0}$ & $*$ & 0.00 & 0.00 & 0.00 & 0.00 \\
$\mathrm{GRW}_{3}$ & $\mathbf{0 . 0 7}$ & $*$ & 0.00 & 0.00 & 0.00 \\
$\mathrm{STV}_{0}$ & $\mathbf{0 . 1 3}$ & $\mathbf{0 . 1 9}$ & $*$ & 0.00 & 0.00 \\
$\mathrm{STV}_{2 \mathrm{~N}}$ & $\mathbf{0 . 1 4}$ & $\mathbf{0 . 1 8}$ & $\mathbf{0 . 0 3}$ & $*$ & 0.00 \\
$\mathrm{STV}_{2 \mathrm{P}}$ & $\mathbf{0 . 1 2}$ & $\mathbf{0 . 1 7}$ & $\mathbf{0 . 0 3}$ & $\mathbf{0 . 0 2}$ & $*$ \\
\hline
\end{tabular}



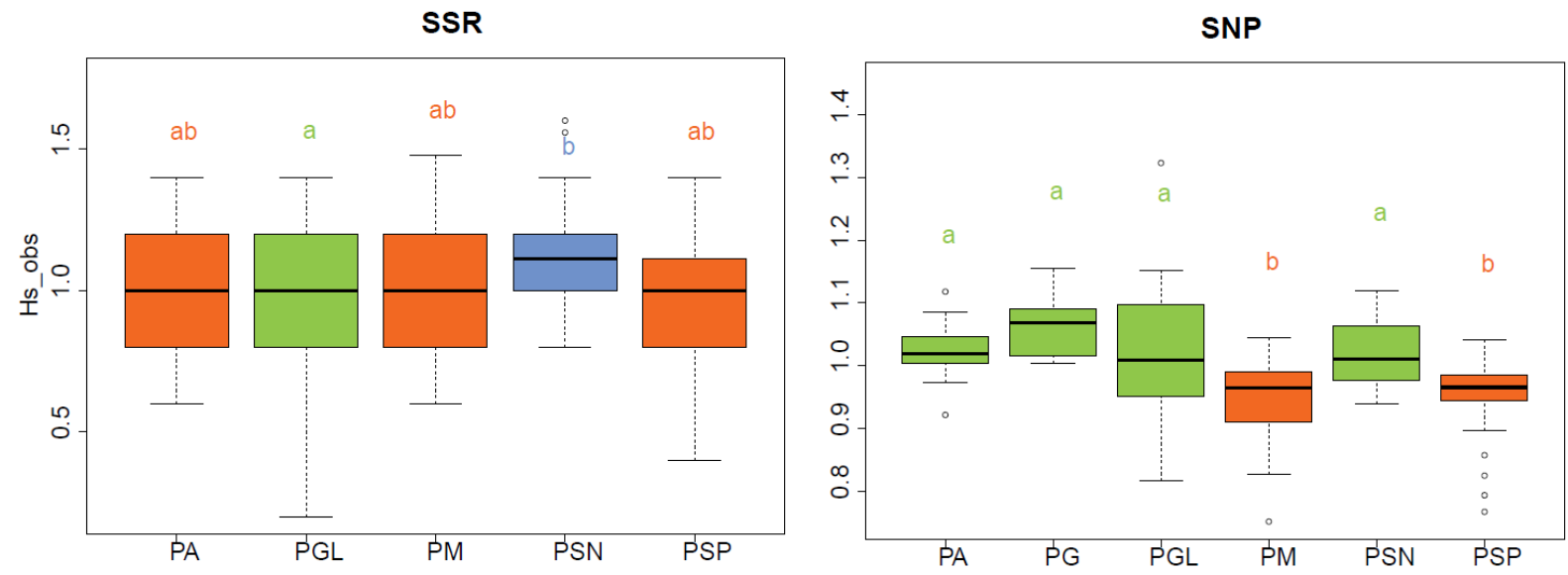

Figure 1 

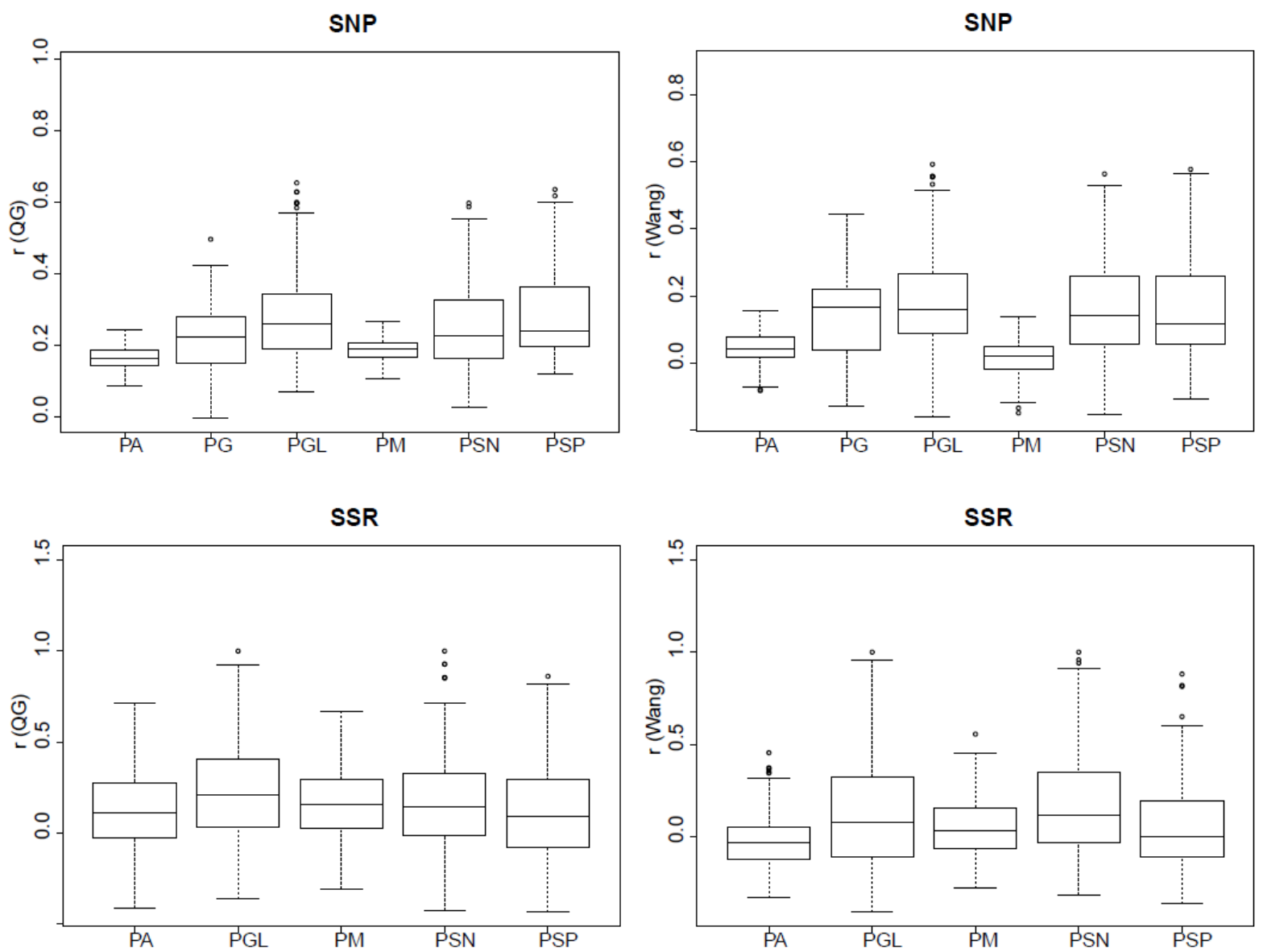

Figure 2 

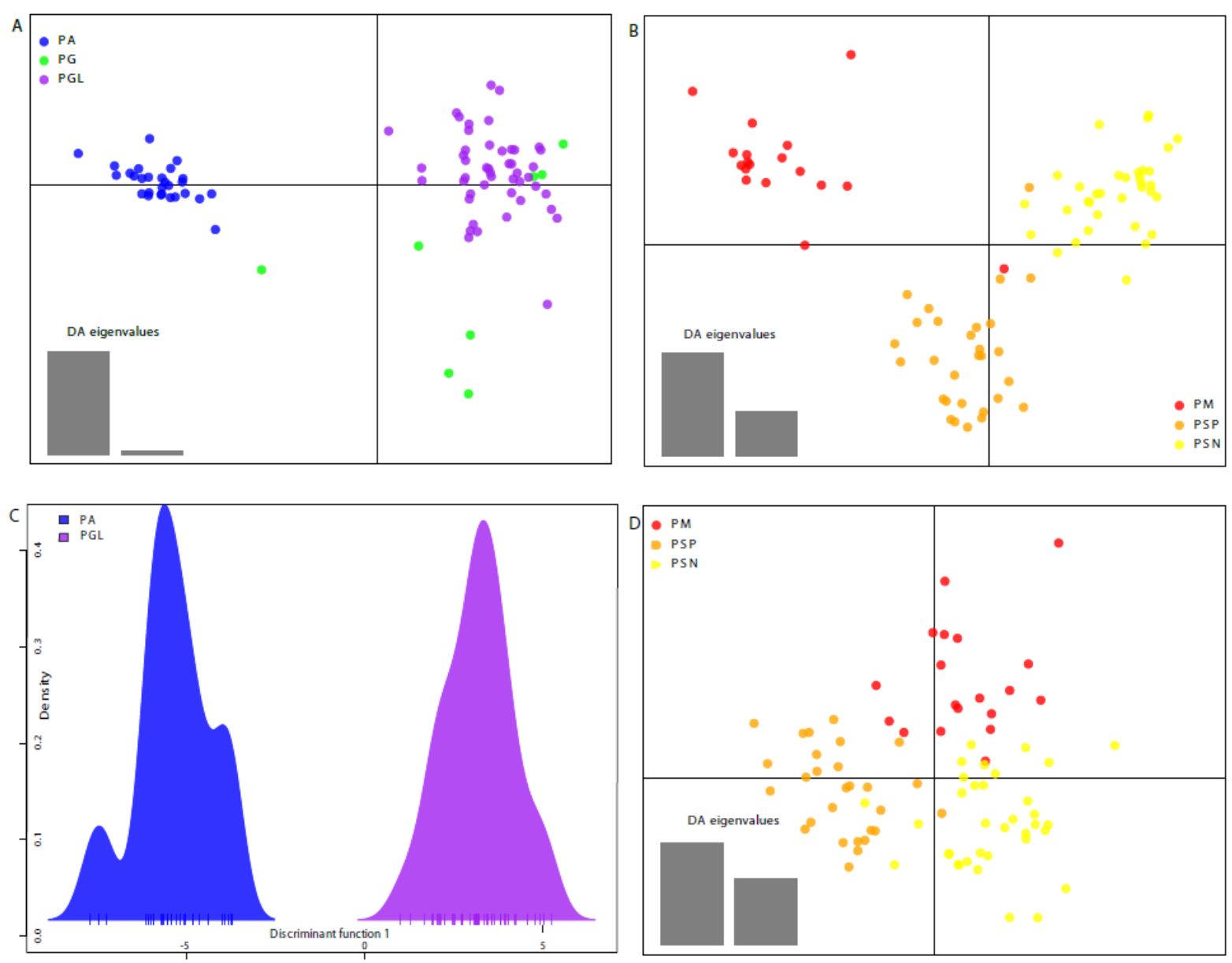

Figure 3 
Fig. 1. Boxplots with individual standardised heterozygosity (Hs_obs) for the microsatellite (left) and SNP (right) genotypes. Clusters with the same letter code and color are not significantly different from each other (Tukey multiple comparison of means, $\mathrm{P}<0.05)$. For sample codes see Table 1.

Fig. 2. Boxplots of pairwise relatedness estimates within the groups calculated according to the methods of Queller and Goodnight (1989) (r(QG), left) and Wang (2002) (r(Wang), right) for both SNP (top) and microsatellite (bottom) genotypes. For sample codes see Table 1.

Fig. 3. Scatterplot showing the first two principal components of the principal component analyses (DAPC). A: SNP data of the growth line, B: SNP data of the starvation line, C: microsatellite data of the growth line (the plot visualises the variability of the first discriminant function and the relative densities), D: microsatellite data of the starvation line. Each point represents one individual and groups are colour coded (see individual legends). The insets of the bar plot display the eigenvalues of the principal components in relative magnitude and illustrates the variation explained. 